\title{
Iglesia y democracia: eclesiología política o la politización de los cristianos
}

\author{
P. Hernán Rodas ${ }^{\star}$
}

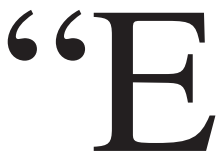

I procurador general de los EE. UU. Johon Ashcroft afirma que en su país se tiene "a Jesús como Rey" mientras que Tom Delay, republicano de la Cámara de Diputados, declara que Dios le confió la tarea de dar "una visión bíblica del mundo" a la política estadounidense. El presidente Bush se siente investido del poder, de la virtud cristiana cuando afirma "La libertad a la que estamos apegados no es el don de América al mundo, sino es el don de Dios a la humanidad", "los acontecimientos no son movidos por cambios ciegos ni por el azar, sino por la mano de un Dios justo, fiel". "Vamos a exportar la muerte y la violencia a los cuatro rincones del planeta para defender nuestra gran nación". Insisten en la separación entre la Iglesia y el Estado, no por miedo a que el poder del Estado afecte a la religión, sino por miedo deque el poder de la religión afecte al Estado. "Estados Unidos tiene el privilegio infinito de cumplir su destino y salvar al mundo". Afganistán, Irak se suman a las masacres e invasiones que los EE. UU. han realizado desde 1840 que invadieron México con la bendición de Dios sobre sus caballos y fusiles, hoy sobre sus misiles". ${ }^{1}$

\footnotetext{
* Vicario de Pastoral de la Diócesis de Cuenca. Director Ejecutivo del Centro de Educación y Capacitación de Cuenca (CECCA).

${ }^{1}$ Le Monde diplomatique. Lewis H. Paphan. Pág. 32-Julio 2003.
} 
El tema de la relación entre la fe y la política, la Iglesia y el Estado está siempre presente y es motivo de acalorados debates en todo el mundo. La moderna Unión Europea, debatió últimamente la necesidad o no de mencionar en su constitución al cristianismo como parte de sus raíces culturales o en muchos países regresa el tema de la enseñanza religiosa en las escuelas estatales o los neoconfesionalismos de los fundamentalismos conservadores.

Un orden social injusto, corrupto, de permanente explotación que perdió justificación en su propio discurso democrático, busca su última justificación y consistencia en el nombre de Dios o pidiendo a la jerarquía que sea intermediaria en los conflictos del Estado a nombre de que el pueblo cree en la Iglesia. El llamado ya no es siquiera a nombre de una determinada ética de valores cristianos relacionada con la política, en la que el Evangelio pasando por mediciones ideológicas, doctrinarias justifica decisiones políticas programáticas, el llamado de intermediación se hace a nombre del peso social que ejerce la Iglesia como estructura institucional de lo sagrado.

La reacción del pueblo, hoy, ante el permanente intento de los sectores dominantes de usar a favor de sus intereses de clase, esa plusvalía simbólica producida por el pueblo en el ámbito religioso nos muestra que ciertamente hemos avanzado en la lectura de la relación de la fe y la política. La relación no se da en abstracto, sino se inscribe en una teología de sujetos sociales concretos; las comunidades cristianas campesinas, los movimientos de renovación social y eclesial en el campo y la ciudad, en los que la fe cristiana no juega ya el papel de legitimación religiosa de una práctica política, ni es solamente un llamado o motivación desde la fe al compromiso político, sino la expresión humana de que la fe cristiana es creadora de sentido liberador en las prácticas histórico-políticas. Vamos a analizar detenidamente estas afirmaciones. 


\section{Gobierno por la gracia de Dios}

Recordemos que desde que llega Colón a nuestra Patria Grande y luego los cañaris son despojados de sus tierras y, mediante el Cabildo cuencano, se reparte las tierras y se forman las haciendas; manera originaria de acumulación con la explotación de los indígenas, ya se lo hace a nombre de Dios. La teología política de ese tiempo justifica la "razón de Estado", El Rey de España, los Gobernadores, los Caciques gobiernan "por la gracia de Dios". Esta teología política ha estado presente a lo largo de nuestra vida republicana y se ha manifestado de muchas maneras. La Iglesia católica y su jerarquía, durante siglos, va conformando su identidad en esta relación con el Estado y particularmente con los grupos de poder conservador, siendo ella misma una gran terrateniente. La confrontación de los partidos liberal y conservador a lo largo de la vida republicana tiene como eje el uso, que los terratenientes de la Sierra, hacen de lo religioso para justificar, con el nombre de Dios, un sistema de explotación.

Las desavenencias entre Iglesia y Estado en la construcción de la Nación, en la práctica Democrática, ha estado siempre presente. Ya en la independencia la Santa Sede se colocó del lado de España y los obispos y el clero se dividieron para luego vivir el conflicto provocado por el derecho de Patronato que convertía a los obispos y sacerdotes en funcionarios del Estado, que participaba en la elección de obispos, organización del culto y cobro del diezmo. Muchos eclesiásticos participan como diputados, constituyentes. La Iglesia incrementó sus propiedades, formando una fuente común con los intereses de los hacendados serranos.

Se suprimió el Patronato y con gran tensión entre los grupos de poder y el clero se firmó el Concordato de la Santa Sede. "No estaba en la mente del presidente García Moreno, quien suscribió el Concordato, la implementación 
de una democracia representativa con un sistema de partidos, sino el poder autocrático, apoyado en una única institución encargada de canalizar el control político, "la Religión Católica es el único vínculo que nos queda en un país dividido por los intereses y pasiones de partidos, localidades y de razas, decía García Moreno en el Congreso de 1873, la Iglesia se convirtió en su partido, encargado de la regeneración moral y de la modernización del Ecuador", luego de la muerte del Presidente la Iglesia articuló al Partido Conservador que fue por casi 50 años un apéndice de la Iglesia Católica. Con el liberalismo se rompen las relaciones con la Santa Sede, la Iglesia perdió personería pública por la Constituyente de $1906^{2}$.

En 1937 el Gobierno de Páez suscribe con Roma un "Modus Vivendi" separando las dos potestades. La Iglesia fue reconocida en sus atribuciones espirituales, con personería jurídica.

El conflicto de los sectores dominantes se resuelve con una crítica política a la Iglesia, el rechazo de la presencia de lo religioso en el espacio del Estado. El ámbito público será laico y lo religioso será relegado al espacio de la Iglesia que no puede intervenir en "política" es decir en el espacio de los intereses de los dueños del país: los políticos al poder y los religiosos a la Iglesia. Esta teología política, privatiza la religión, la religión pertenece a la esfera de lo privado, está manejada por los obispos que perteneciendo institucionalmente al ámbito del poder, anteriormente también por el poder económico, cultural y oficial, sin embargo queda reducido su espacio al ámbito ritual, doctrinario, sin pronunciamiento político ante el Estado.

La división dualista: materia, espíritu, cuerpo-alma, esfera de lo terrenal y esfera de lo espiritual, lo político y lo

\footnotetext{
2 MONCAYO ALBAN, Carlos: Cristianismo y política. Tomo 4, 1998. Pág. 175. TOBAR DONOSO, Julio: La Legislación liberal y la Iglesia Católica en el Ecuador. Quito. 2001.
} 
religioso, es una clara expresión de esta teología que hoy regresa con fuerza a los sectores neoconservadores, en muchos movimientos religiosos dentro y fuera de la Iglesia, en los fundamentalismos religiosos que se tornan violentos defendiendo la esfera de lo religioso frente a la supuesta politización de la fe. Hasta el Banco Mundial, el FMI de pronto adquieren una argumentación teológica, para sustentar sus estrategias.

\section{Carácter público de la fe}

En las últimas décadas de forma dolorosa y con el martirio de miles de cristianos, se ha ido construyendo, en América Latina, otra teología política, recuperando el carácter público de la fe, ya no como antes, justificando un sistema de muerte, ni re-colocando el cristianismo como religión de Estado, preocupada que el nombre de Dios o de cristiano esté en la Constitución, en los partidos, u otras instancias de lo político.

Esta construcción de una nueva teología política ha supuesto un enorme esfuerzo teórico-práctico para reformular el espacio de lo político y el sentido político de la fe cristiana, paso a paso en años se ha superado en algunos sectores de la Iglesia, los nuevos reduccionismos de la fe y se han enfrentado los desafíos teológicos y políticos que implican la construcción de una nueva identidad liberadora teológico-política, una nueva relación de la fe y la política.

La Iglesia tradicional existió durante siglos en relación estrecha con los sectores dominantes, ese fue su "lugar" desde la colonización y luego con los sectores terratenientes, conservadores. La Iglesia institucionalmente está configurada de tal forma que su interlocutor natural es el Estado como órgano de los grupos de poder y este hecho le ubica frente a la política, en corresponsabilidad del proceso democrático. 
La Iglesia sigue siendo un pilar de la nación mediante la producción y reproducción de los símbolos patrios y nacionales; por ejemplo, la Basílica del Voto Nacional, Los Te Deum, la relación con el Ejército, con el Obispo y Vicarías Castrenses y todas las expresiones en las que el poder del Estado y el poder de la Iglesia son presentados como expresión de nacionalidad.

Cuando sectores de la Iglesia cambian de "lugar social" y comienzan a identificarse con las condiciones de vida de los sectores empobrecidos, marginados, con los indígenas, los negros, etc. se van formando nuevos rasgos de identidad eclesial. Desde el Vaticano II la Iglesia de América Latina se pronuncia a través de sus documentos a favor de los pobres y descubre desde la práctica pastoral la dimensión política del pobre, de los pobres como, sujeto social que tiene una nueva lectura de su situación y lo hace iluminado por la Palabra de Dios. Digamos que los sectores populares inicialmente animados desde la fe, se van alejando del Estado y ubicándose en la "sociedad civil" y entre los más pobres y desde allí hace una relectura de la historia del Estado, de su carácter, desde esta relectura redefine su dimensión política; como decía Mons. Romero, "el conflicto no es entre la Iglesia y el Gobierno, es entre el Gobierno y el pueblo y la Iglesia está con el pueblo".

El nuevo referente de este modelo de Iglesia ya no es el Estado, sino las organizaciones del pueblo y esto le lleva a una nueva experiencia política entendida como una práctica organizativa, de construcción de nuevos sujetos sociales de transformación social; de esta forma la Iglesia ha participado en la formación de un nuevo "tejido social popular" en la emergencia de nuevos sujetos sociales.

Esta nueva práctica política cristiana, no nace de ideologías, no es simple motivación para adherirse a posturas políticas pre-fabricadas, es simplemente una nueva forma de ser cristianos, es una naciente identidad, individual y 
colectiva que se construye en la práctica en los símbolos, en las opciones, en la continuidad de una práctica coherente. El cambio de lugar social, la opción de los pobres, ha desprivatizado y ha sacado de los templos a la fe, para comprometerle con la justicia, la verdad, el sentido comunitario, expresada en las luchas populares, en la identificación con el mundo social y cultural del pueblo. La dimensión política de la fe se ha expresado en el rechazo al actual sistema político, económico. En la denuncia profética de los mecanismos de dominación a través de la Deuda Externa, el TLC, de la violencia del sistema neoliberal que pisotea los más elementales derechos de las personas y pone el dinero y el lucro como criterios principales de la vida social.

Rechazo al sistema ideológico del "pensamiento único" del mercado total, de la cultura del consumo e individualismo que desintegra y dispersa al pueblo pobre.

La dimensión política de la fe a partir de la experiencia, de la práctica cristiana y no como una ideología cristiana o una estrategia política afirma en los documentos de la Iglesia de América Latina y Ecuador: la dignidad de los seres humanos, la dignidad de los pueblos, hace una afirmación de la democracia, como un sistema en el que prima la razón sobre la violencia, la libertad y los derechos no solo escritos en la constitución sino una democracia real, un sistema de consensos y no de imposiciones y arbitrariedades.

La afirmación en los derechos humanos como contenido de una política orientada a conseguir plenitud de vida económica, cultural, social, en la que las grandes mayorías, los postergados de siempre, van gestando un proyecto de una nueva sociedad, una nueva civilización, no solo formalmente en el nivel político, sino en las decisiones, en la construcción de la vida económica, en la producción cultural, en los beneficios de la vida social.

La afirmación de una cultura solidaria. Comunitaria, como eje de una nueva cultura popular liberadora, superan- 
do la elitisación, la discriminación en una relación activa, participativa del pueblo y la cultura.

Oficialmente la Iglesia de América Latina hace un conjunto de opciones, de relecturas de la sociedad, de sus mecanismos de opresión y pecado y estas descansan en las prácticas eclesiales de la base.

Los grupos cristianos se politizan y van paulatinamente adquiriendo un perfil político en un largo proceso a partir de la práctica, de la formación, de información política, de los signos que constituyen su identidad cristiana básica; la lucha por la justicia, la verdad, el amor y la paz como signos de la construcción del proyecto de Dios, la Palabra de Dios y una espiritualidad que nace de esa santidad política.

En estas décadas, sectores del cristianismo se renuevan y revitalizan en estrecha vinculación con este traslado del lugar social de la fe, la inserción en el mundo popular y la identificación con las aspiraciones y luchas del pueblo y los sueños por construir una sociedad lo más cercana al proyecto de Dios. La Iglesia Ecuatoriana en, opciones pastorales, expresaba su proyecto de Iglesia de esta forma: "Evangelizar preferentemente a los pobres, con los pobres y desde los pobres, a la luz del mensaje de Jesús sobre la liberación integral".

"Para esto se impone una toma de conciencia que prepare y vaya creando signos de un orden nuevo que según el plan divino debe ir forjándose en la historia. De este proyecto depende la verdadera liberación de nuestro pueblo oprimido y la autenticidad de nuestra fe en Cristo". OP: $52-55^{3}$.

\section{Reduccionismos de la fe y la política}

La fe es ante todo experiencia de sentido, tiene un carácter liberador; la fe proclamada, vivida y celebrada a tra-

${ }^{3}$ OPCIONES PASTORALES. Conferencia Episcopal Ecuatoriana. Sep. 1980. 
vés de la pastoral, catequética, litúrgica y social es una proclamación del evangelio, que es buena nueva para todos, pero especialmente para los pobres. El sentido jubilar de liberación, descanso, perdón de deudas, recuperación de las condiciones sociales y económicas de una vida digna: trabajo, vivienda, libertad, dignidad, sentido de pueblo, de familia unida por la solidaridad, el amor, ese es el mensaje de Jesús. Este anuncio y práctica es en sí misma política.

Lo cristiano no es entonces un espacio pre-político, para de allí pasar al terreno de la política expresada en los partidos o movimientos políticos. La fe no es solo una exigencia de compromiso que nos lleva a participar en el mundo de la política, en el bien común, en la democracia como un punto de partida, una exigencia ética que termina, donde empieza la lógica de lo político partidario.

Cuando afirmamos "la fe debe llevarnos al compromiso", señalamos un aspecto importante pero olvidamos que la fe en sí misma tiene ya un sentido liberador, transformador, de conversión personal y social. Este reduccionismo de la fe va unido también entre nosotros a un reduccinismo de la política.

Los sectores dominantes, con todos sus rituales del poder, nos han llevado a pensar que la política la hacen y practican los políticos solamente y que se expresa y manifiesta a través de los partidos que son los intermediarios entre la sociedad civil y el Estado y que recogiendo el sentir del pueblo a través del voto se da el juego democrático.

Esta concepción estrecha de la política y desconoce que en muchas organizaciones e instancias se concretan compromisos liberadores, de transformación social, que los partidos, las elites políticas, no son los que condensan las aspiraciones del pueblo y por lo tanto lo representan. La actual crisis de representatividad de los partidos políticos, nos muestra el final de esta práctica que reduce lo político a lo partidario, en el que la fe supuestamente no tiene nada 
que aportar ni decir frente a las categorías analíticas e ideológicas de la política.

El sistema piramidal en las organizaciones populares, sindicales, campesinas, políticas, partidarias entró en crisis, entre otras razones por el reduccionismo del proyecto del pueblo, de la organización, a la elite dirigente. El proyecto popular es un proyecto histórico de cambio social y es el resultado de un esfuerzo colectivo de las distintas instituciones populares a partir de su experiencia, la politización del pueblo, es la potenciación creadora de sus experiencias, su despertar como sujeto histórico activo, que va construyendo su propio camino. Pero, generalmente, hablar de toma de conciencia, organización, politización del pueblo es hablar del aprendizaje de una ideología, el conocimiento de su programa, de una estrategia elaborada por la dirigencia, por la elite, el partido, este reduccionismo lleva a pensar que la politización de los cristianos es sumarse a estos proyectos políticos ya definidos, en este sentido cabe la pregunta, ¿el aporte de los cristianos al proyecto liberador, es solo sumarse a algo pre-definido? O tiene algo propio que decir en los procesos de construcción democrática.

Entre los grupos cristianos, la politización se da a veces desde la ética del compromiso sin mayor reflexión y análisis crítico sobre la realidad social, política y con cierto sentido de inferioridad frente a las elites de los partidos y movimientos. Si la política es transformación de las estructuras, creación de una nueva forma de relación social, es necesario que sus planteamientos, estrategias, programas conduzcan realmente a esas transformaciones. La politización, impulsada como compromiso desde la fe, solamente lleva con frecuencia al encuentro del radicalismo verbal, ejerce un atractivo por su radicalidad y no por su coherencia política, la política entonces, se hace más testimonial que realmente transformadora. Muchos grupos cristianos han sufrido 
frustraciones por este radicalismo ético-político que no llega nunca a la creación de una alternativa política real.

La autonomía del movimiento popular exige que la Iglesia no se convierta en poder paralelo y sea realmente comunidad de fe. La exigencia de constante conversión a su dimensión sacramental y creyente de la misma forma esta exigencia teológica se convierte para el movimiento popular en una exigencia política basando su poder en el de clase y no al amparo del poder eclesiástico.

Esta exigencia de acompañamiento al proceso de organización popular nos ha llevado de lleno a afrontar los distintos aspectos del proceso; lo político, lo orgánico, lo teórico.

La política referida al movimiento popular y al pueblo como sujeto histórico de cambio; lo orgánico referido a todas las formas de organización e instituciones que va creando el pueblo en su proceso de liberación y la instancia teórica que es la que transforma la experiencia de organización lucha del pueblo en teoría de cambio.

La práctica política no es pues una categoría abstracta sino que está cargada de toda una racionalidad histórica concreta, en lo político, orgánico y teórico.

Esta práctica supone un sujeto histórico determinado que está presente en el conjunto de fuerzas sociales que buscan una sociedad justa. Supone un proyecto histórico, una alternativa que va diseñándose como sociedad del futuro en el nuevo contexto global.

La construcción del hombre y mujer nuevos, de la nueva civilización supone a la vez elementos indispensables para su construcción: un programa, una estrategia, una táctica. Esta práctica política tiene su propia racionalidad y exigencia para el cristiano. La identificación es plena, sin ninguna idea anterior, sin ningún intento de bautizar la práctica política. 
El sentido cristiano se descubre y construye inmerso en la lucha de los pobres. Hay como una pérdida y recuperación de la identidad cristiana que se realiza en la práctica política. Eso implica para el cristiano un proceso de continua conversión, la entrega de la propia existencia identificada con la causa del pobre. La práctica política, orgánica y teórica nos lleva a encontrar un nuevo sentido al evangelio, a la figura de Jesús, a nuestra oración, a nuestro compromiso, a la relectura de la Doctrina Social de la Iglesia, a nuestras celebraciones culturales, a nuestra espiritualidad.

\section{Democracia y Estado}

El neoliberalismo disfrazado hábilmente de discurso democrático nos va imponiendo imperceptiblemente la razón capitalista - imperialista que nos despoja y nos lleva a una situación de mayor miseria y exclusión.

Definitivamente el estado capitalista se ha agotado para dar respuestas a una población creciente, marginada y hundida en la miseria. El espacio económico para el reformismo en el Estado se estrechan, las reformas se bloquearon, no queda posibilidad de una integración económica en la población, este panorama se agrava más con el peso de la deuda externa. Cuando las esperanzas de cambio se esfuman, cuando las promesas no se cumplen, la democracia liberal de masas sufre una crisis de legitimidad y los movimientos populares están más allá del estado burgués.

En este contexto, la sociedad burguesa redefine la democracia, convirtiéndose en una democracia mítica de la paz social, de diálogo y concertación social, de mutua tolerancia, de pluralismo más allá de los problemas concretos, la democracia como paraíso de diálogo donde se enfrentan opiniones y no intereses de clase. Se llama a guardar un comportamiento civilizado y democrático como parte de una ética de relaciones sociales entre grupos humanos sin pro- 
blemas económicos o con aparentes problemas comunes porque todos tenemos el sagrado deber de salvar la democracia y la patria.

Se esconde conscientemente el tema de las condiciones económico-sociales, de la organización democrática del poder político, es una democracia que no habla de intereses sino solamente de diálogos y concertaciones porque hay un solo interés que la mueve y que no se le nombra, es la Democracia de la Seguridad Nacional, que se hace plena solo cuando el pueblo deja de ser soberano, guarda su independencia, distanciándose del estado burgués. El utopismo democrático del actual estado burgués busca salvar a la democracia de las reivindicaciones populares, liberan a la democracia del pueblo: el capitalismo oprime cada vez con más dureza y continúa con su origen antipopular y lo hace en nombre de una democracia que es la negación de toda democracia. Por esta razón, es necesario retomar y analizar los conceptos, las representaciones y la realidad de la democracia en el estado actual.

\section{Democracia liberal en crisis}

La noción de democracia determina, antes que nada, una forma de gobierno, por oposición de las formas autoritarias, en una democracia; la tarea de gobernar corresponde al pueblo en general, por eso deberíamos hablar más bien de un auto gobierno y esto es precisamente lo que define la soberanía popular, clave de la verdadera democracia.

En la idea del gobierno por el pueblo se unen el sujeto y el objeto del gobierno, la identidad de dirigentes y dirigidos, pero en el ejercicio de gobierno se va consolidando la separación entre Estado y Sociedad, entre lo político y lo social, separación que es requerida por los regímenes liberales modernos y les ha permitido romper la noción de identidad democrática y distinguir entre democracia política y 
democracia social, dejando de lado el contenido social, reduciendo la democracia al procedimiento político para elegir y autorizar gobiernos.

En la democracia liberal se separa radicalmente la identidad del pueblo y la representación del mismo. La identidad encuentra su manifestación principal en el acto de votar, de elegir, de sufragar, se supone que allí el pueblo "expresa su voluntad soberana" y es vehículo de identidad social.

Con el enunciado de que el voto es universal, igualitario e ilustrado se pretende la identidad entre gobernantes y gobernados, dirigentes y dirigidos, traduciendo así la soberanía popular.

La representación, los gobernantes elegidos; en cambio, viven y se alimentan de la separación entre gobernantes y gobernados, adquieren la estructura de autoridad estatal, haciendo visible la autonomía de lo político, frenando, cortando el impulso de identidad y creando una barrera entre dirigentes y dirigidos.

La identidad proclamada en la democracia moderna es la homogeneidad formal de derechos y obligaciones; todos somos ciudadanos con los mismos derechos y obligaciones, iguales ante la ley, hijos todos de la madre patria, lo que supone una democracia económica, social, donde todos disponen de los medios necesarios para vivir con dignidad, según lo proclama la ley. Justamente esta contradicción llevada por el sistema a niveles catastróficos y que atentan a la vida del pueblo, hace que se reprima todo intento de participación de la sociedad civil en la construcción de la identidad sustantiva entre dirigentes y dirigidos, eliminando los obstáculos conceptuales que permitan ver con lucidez que una sociedad dividida en clases, con intereses contrapuestos, con alto nivel de corrupción, no puede ser sostenida por procedimientos democráticos.

La democracia burguesa, distingue por eso entre derechos civiles y derechos políticos, derechos del hombre y 
derechos del ciudadano. Se acepta la igualdad de los derechos civiles; derecho a la propiedad, asociación, expresión, ante la ley, pero se hace una diferenciación para los derechos políticos, no todos merecen los derechos ciudadanos.

El mérito político está constituido por la posesión de bienes, propiedades, cultura, raza, de esta forma, por principio en la democracia burguesa, el pueblo puede elegir a sus dirigentes, pero no controla su actividad, estos imponen la autonomía del estado político y la despolitización de la sociedad civil.

El pueblo renuncia a su poder y lo entrega por un tiempo a un alcalde, diputado, presidente, etc., elegido popularmente para que realice las tareas gubernativas y actúe por el pueblo, de esta forma el pueblo queda vulnerable a los atropellos del estado político, perdiendo su participación directa, y su capacidad de auto determinación. La democracia política queda vacía, despojada de contenido, reducida al simple hecho de votar para elegir representantes nombrados de antemano por los monopolios políticos, sustentados por las elites rectoras, la partidocracia.

La identidad entre el estado y la sociedad civil es solo formal. En tanto que trabajadores y empresarios, campesinos y terratenientes, todos gozan de la igualdad política formando la voluntad estatal y ejerciendo el poder político a través del derecho a votar universal e igualitariamente, no se expresa políticamente la hegemonía de clase, esta se manifiesta en toda su crudeza en lo económico.

Por otro lado en la sociedad nos encontramos con un fraccionamiento de grupos y organizaciones que buscan objetivos políticos-económicos bien definidos. El ciudadano común no puede influir en las decisiones del gobierno, son los partidos políticos los que ejercen presión, oposición o legitiman los intereses de los grupos de poder.

La democracia así entendida necesita entonces de un sistema partidario, teniendo como expresión suprema el 
parlamentarismo, la autoridad y el poder de la mayoría sobre la minoría, rompiendo y fraccionando aún más el elemento de identidad democrática.

Los teóricos de la democracia burguesa dicen que no es posible hoy, resucitar las asambleas universales de la época clásica, hay una moderna división del trabajo y la representación parlamentaria es una expresión de la misma, así como la elección de dirigentes, la democracia es solo un método político, recalcan y como tal no avanza a la igualdad política, social o económica, como método tiene sus propios elementos como son los compromisos, las transacciones, las alianzas, la democracia es el punto medio entre las oscilaciones del pedúnculo político hacia la derecha y la izquierda. (Kelsen) ${ }^{4}$.

La democracia es en realidad, una dictadura, ya que se basa en el principio del dominio hegemónico de la mayoría sobre la minoría, en una sociedad donde los mismos partidos burgueses son grupos familiares, casi empresas políticas fundadas en el poder económico de pocos, los candidatos y dirigentes no son designados por la colectividad social de los dirigidos, sino que se alza sobre ellos. Una democracia, debe reposar sobre una base social homogénea, sobre una democracia social y económica. Una forma de gobierno que se constituye al margen de una base social, no es auténticamente democrática y en la práctica nada impide que la supuesta mayoría legal instalada en el poder, elimine los derechos de la minoría y la deje sin protección frente al imperio de la mayoría.

El requerimiento democrático no puede ser solo político -un ciudadano- un voto, sino el reconocimiento real y efectivo del derecho del ciudadano que vota a una vida digna, al desarrollo de sus facultades, a vivir una existencia plenamente humana. Un espacio auténticamente democrá-

${ }^{4}$ Citado por Renato Cristi en "Democracia política versus democracia social".

Pág. 27. Kelsen-Esencia y valor de la democracia. Guadalajara-Madrid. 1970. 
tico produce avance intelectual, creativo, ético, eficiencia práctica, que considera al ser humano no solo como consumidor de utilidades, y el poder como capacidad de dominio y control de unos individuos sobre otros.

Alain Touraine dice a propósito: "Democracia no es una meta en sí misma; es la condición institucional indispensable para la creación del mundo por parte de unos actores particulares, diferentes entre sí pero que producen en conjunto el discurso nunca completado, nunca unificado, de la humanidad. Si no es consciente de su papel al servicio de los sujetos personales, la democracia se degrada en mecanismos institucionales que resulta fácil poner al servicio de los más poderosos, de los aparatos y los grupos que acumularon suficientes recursos para imponer su poder a una sociedad que no opone ninguna barrera a su conquista".

"Es a causa de que la sociedad está dominada por poderes que la acción democrática consiste ante todo en oponer, a unas prácticas y unas reglas institucionales que sirven en gran mediada a la protección del poder de los dominadores, una voluntad colectiva y personal de liberación, que es muy otra cosa que la búsqueda racional del interés, que trastorna el orden, derriba las garantías institucionales de la dominación y recurre también a unos valores culturales universales contra un poder al que acusa de estar al servicio de intereses particulares"

\section{Democracia-democratización-democracia de seguridad nacional}

Las tensiones entre democracia formal, democracia social, democracia económica, son cada vez más insostenibles para el Imperio y los grupos dominantes. La democra-

\footnotetext{
5 TOURAINE, Alain. “¿Qué es la democracia?” Pág. 192. Fondo de cultura económica. México. 2004.
} 
cia liberal de minorías a finales del siglo XIX, se transforma en democracia liberal de masas, estabilizándose después de la segunda guerra mundial y la derrota de los fascismos. Internamente descansa sobre el voto universal y externamente sobre la descolonización, se proclama la soberanía de los Estados y la ciudadanía de todos los habitantes, aunque en nuestro caso ecuatoriano el paso de la Democracia Liberal de Minorías a la de Masas, ha sido lenta y a costa de tensiones violentas, los indios, los cholos, las mujeres, los analfabetos, los pobres, no fueron ciudadanos según la primera constitución y se va entrando en la soberanía popular de la tradición burguesa, solamente con la modernización del Estado ecuatoriano.

"En la democracia liberal de masas, hay un solo poder que es a la vez representativo por elecciones y portador de la soberanía. La división de poderes; ejecutivo, legislativo y judicial tiene lugar al interior de este único poder soberano y representativo, un poder que está limitado por las propias relaciones sociales de producción, es la manifestación política de las relaciones capitalistas de producción y por lo tanto del poder burgués. La burguesía se considera a si mismo portadora del espíritu de la constitución, de las instituciones sagradas del estado y se enfrentan contra el poder político soberano y elegido por sus propios mecanismos de democracia formal, cuando desde el estado se pone en cuestión el carácter burgués del mismo". ${ }^{6}$

Han abundado los procesos de democratización, contando todos con el visto bueno y el auspicio de los EE.UU., en el intento de frenar las dictaduras de Seguridad Nacional por las que las Fuerzas Armadas se arrogaron y se constituyeron en poder político. De brazo armado del poder político civil se transforman en portadores del legítimo poder

\footnotetext{
${ }^{6}$ CRISTI, Renato en democracia política versus democracia social. Ediciones Rehue. Chile. 1988. Pág. 27.
} 
político, en jueces de la sociedad civil y en portadores de la ideología y de un proyecto económico social para transformar la sociedad civil basándose en el poder de las armas.

Esta transformación de las Fuerzas Armadas se apoya en un sistema mundial cuyo centro es EE.UU. Los procesos de democratización aparecieron en los estados de seguridad nacional. Los gobiernos militares y el escándalo de la represión en varios países obligan a procesos electorales y surgimiento de gobiernos civiles, pero ya no regresaremos a la democracia liberal de masas, surge por el contrario un nuevo tipo de democracia de seguridad nacional, una democracia aún más limitada, controlable. Una democracia con un nuevo poder, con un nuevo lugar para la soberanía.

Muchas veces constituciones que regían la vida política de los países, ya no expresan la soberanía civil y sus parlamentos fueron reducidos en la práctica a espacios de propuestas que deben recibir el visto bueno de las Fuerzas Armadas. El Ejército es el nuevo lugar de la soberanía. Los gobiernos democráticos surgidos en este período, son gobiernos civiles, elegidos por la soberanía popular, con autonomía frente al Ejército, pero sin soberanía; hay un doble poder político que se divide en el primer caso en poderes para la sociedad civil y otro que es el Ejército que tiene poder soberano.

Esta nueva forma de democracia es la respuesta a la creciente demanda de las grandes mayorías que a pesar de la fuerte represión, masacre, persecución no han callado y dejado de movilizarse en defensa de la vida y de condiciones humanas dignas. En la medida que el sistema capitalista no logra solucionar los problemas de las grandes mayorías, ni logra la integración de la población a la economía, el voto universal lleva a la transformación de la democracia liberal de masas y atenta contra la sociedad burguesa. La democracia de seguridad nacional es la salida a la contra- 
dicción de la democracia liberal que en formalidad reconoce la necesidad de transformación en democracia y libertad y en la práctica no puede promover su propia destrucción cuando las mayorías votan por transformaciones radicales, entre la espada y la pared o vuelve a la democracia liberal de minorías o tiene que defender "su democracia" del pueblo, dando la soberanía al Ejército.

Los llamados pactos sociales, concertación social y diálogos civilizados y democráticos a los que han recurrido los gobiernos social-demócratas de América Latina, están dentro de una estrategia que intenta fijar los límites del quehacer político, dando validez en la concertación a determinados procedimientos, códigos éticos, aceptando la mediación institucional del estado burgués, para enfrentar las crecientes demandas populares, si el pacto no funciona, el Ejército se encarga de imponer el orden y salvar la democracia. La democracia desde el punto de vista de Washington, a juzgar por su comportamiento, es la de evitar por cualquier medio la consolidación de regímenes políticos que cuestionen su hegemonía.

Contrariamente a la experiencia europea, el estado burgués en América Latina no ha sido capaz de reformas que permitan una mayor integración de la población, por el contrario, las diferencias y la concentración de poder es cada vez mayor, esta situación está reforzada por la creciente deuda externa, migración marina, crisis económica; por lo tanto, ocurre lo contrario, las propuestas de reformas se convierten en surgimiento de movimientos contestatarios, entonces el movimiento popular se convierte en peligro para la democracia y el utopismo democrático burgués llama a las Fuerzas Armadas, la promueve y la instala en defensa de sus intereses económicos ${ }^{7}$.

\footnotetext{
${ }^{7}$ HINKELAMMERT, Franz: Democracia y totalitarismo DEI. 1987.
} 


\section{Democracia y organizaciones populares}

El discurso del Estado Moderno racionaliza la vida social, la democracia es la búsqueda de la racionalidad en la gestión del Estado, en el discurso y en la tramitación de las demandas sociales. Los medios de comunicación y el grado de audiencia de los mismos, juega un papel importante en este proceso.

El pueblo nunca estuvo tan bombardeado de discursos de todo tipo, empeñados todos en constituirlo como sujeto, en darle una identidad; consumidor, progresista, conservador, sindicalista, campesino, empresario, trabajadores, burócratas, comerciantes, especuladores, etc. Desde distintas fuerzas se convoca a los sectores sociales y estos se sienten o no interpelados, la importancia de esta cuestión es evidente en la construcción de un consenso activo para un proyecto democrático, por eso los discursos generales, con referentes teóricos abstractos, con propuestas inemediatistas tan usadas en el movimiento sindical y los partidos políticos, ya no son evidenciados por los grupos sociales a los que se dirigen y han perdido fuerza en manos de sus portadores.

La democracia liberal de masas en Europa y sus remedos en América Latina incorporaron al sistema al movimiento sindical, neutralizándolo como poder contestatario y creando la "nueva clase obrera", que vive en la concertación social. En América Latina se han promocionado sistemáticamente desde el Estado las organizaciones populares, sindicales, campesinas, poblacionales, logrando muchas veces un alto grado de legitimidad. Muchos gobiernos, entre ellos el nuestro, crearon canales legales, financieros, institucionales para incorporar a las organizaciones populares en el sistema democrático burgués. Este reformismo no es simplemente demagógico, sino un esfuerzo real que ha tenido su techo en los límites del propio sistema económico inca- 
paz de generar respuestas válidas, permanentes a la crisis, en el punto en el que muchos movimientos reformistas, nacidos incluso al amparo del Estado se definieron, por un lado, afirmando su existencia en un reformismo ilusorio o redefiniéndose en un reformismo progresista.

En este contexto la tarea de conceptualizar la democracia desde la perspectiva popular es una tarea urgente. Muchas de nuestras organizaciones nacidas, legalizadas y regidas desde el estado, mantienen a su interior con rigidez el sistema parlamentario y la división real entre dirigentes y dirigidos, con una falta total de participación, de comunicación, de mecanismo de identidad, de estructuras institucionales reflejo del sistema imperante, donde los dirigentes se constituyen en portadores y representantes de las necesidades de las bases organizadas, con capacidad para negociar con el estado o decidir por las bases. Su discurso y su acción están entrampadas entre la obtención de mejoras sociales restringidas y condicionadas seriamente por el agotamiento del estado capitalista y un discurso de fines últimos, de nueva sociedad, sin desembocar en la constitución de movimientos sociales fuertes, estables. Se movilizan valores y efectos poderosos para conseguir pequeñísimas ventajas que a veces beneficia más a la cúpula política que a las bases sociales movilizadas. Hoy en día la capacidad de alterar el orden establecido se ve como quimera, las plataformas de lucha y programas están dentro de las condiciones estructurales y el discurso se llena de máximas doctrinales cada vez más débiles ${ }^{8}$.

Cuando la burguesía ha reducido la soberanía popular a la pura ilusión de votar en unas elecciones, no se puede desde el pueblo mantener estructuras organizativas en las que cada cierto tiempo se abren momentos de democracia controlada por la manipulación de votaciones en un

${ }^{8}$ ECUADOR DEBATE: Procesos políticos y democracia. N17. Varios autores. 
congreso o una asamblea, para que rijan los mismo por beneficiosa que sea su presencia. Las cúpulas de dirigentes con escasa representatividad no posibilitan que exista al interior de las organizaciones una efectiva democracia.

Trabajar por recuperar desde el pueblo un auténtico espacio de libertad, de soberanía, de creatividad, de respeto al ser popular, desarrollando una efectiva relación dialógica, creando espacios de libertar que se conjugan en el proceso de liberación, significa hoy una cuestión crucial que significa terminar con la imposición, la toma de decisiones de una minoría, la corrupción, la politiquería, las formas autoritarias, la manipulación ideológica, las formas de represión disfrazadas y esto en todos los espacios de la sociedad, la familia, las relaciones entre vecinos, la escuela, la organización, el poblado, el club deportivo, la Iglesia, etc. o fortalecemos el carácter autoritario manipulador de la democracia burguesa o construimos desde el presente estructuras democráticas, humanas, justas que propicien una vida digna para todos.

\section{El concilio vaticano II: iglesia y sociedad}

Fiel a los llamados del Espíritu, Juan XXIII, convocó al Concilio en medio de profundos cambios sociales, económicos, eclesiales. El Concilio Vaticano II se convirtió en un hecho trascendental para la Iglesia. La figura de la Iglesia encarnada en el mundo actual, aceptando la modernidad como el lugar de reencuentro con Dios, reconociendo a la historia como lugar donde Dios habla e interpela, las situaciones urgentes de la humanidad como referencias para abordar los desafíos presentes. La Iglesia está presente en el mundo pero no es del mundo, es distinta pero no separada y su relación ya no está marcada por el afán de reconquistar poder, de recrear una sociedad cristiana o el anuncio de realidades espirituales. En el Vaticano II la Iglesia se 
ve a sí misma como la comunidad que testimonia al Dios de Jesús, que se encarnó, se hizo historia y promete con su resurrección una transformación, la salvación, como Señor de la historia.

La Constitución Gandium et Spes es sin duda el documento pastoral que apoyada en principios doctrinales, expresa la actitud de la Iglesia hacia el mundo y hacia la humanidad, traza un cuadro sobre las condiciones del hombre moderno y con clara actitud solidaria considera aspectos de la sociedad y de forma particular temas como: las transformación de las condiciones de vida, las aspiraciones de la humanidad, la persona humana, la familia, la comunidad humana, el progreso cultural, la vida económico-social, la comunidad política, la paz, la comunidad internacional.

El documento conciliar, reitera la íntima solidaridad de la Iglesia con la humanidad y con su historia y se dirige no solo a los hijos de la Iglesia sino a toda la humanidad, al mundo, a los hombres como teatro de la historia marcada por las derrotas y victorias (n.s-1-3). La Iglesia sale de sí misma para encontrarse con los hombres y mujeres de nuestro tiempo, con las novedades asombrosas del mundo moderno y con el drama de las grandes mayorías empobrecidas y lo hace para aportar en su solución desde la luz del Evangelio, poniendo al servicio de la humanidad la fuerza del Espíritu y continuar la obra de Cristo, que vino al mundo "para dar testimonio de la verdad, para servir y no para ser servido".

Grandium et Spes, corrobora los principios y las orientaciones dadas anteriormente en las encíclicas: Rerum Novarum, Quadragesimo Anno, Mater et Magistra. Coloca al ser humano autor de toda la vida económica y como centro y fin. La necesidad de honrar y promover la vocación integral del hombre y el bien de la sociedad entera. Insiste

${ }^{9}$ CONCILIO VATICANO II. Editorial Católica BAC. Madrid. 1965. 
en las relaciones internacionales y en la futura organización del mundo jurídicamente unificado, al servicio de relaciones justas entre los pueblos, ya que los bienes que hemos recibido de Dios tienen un fin social. Saliendo de los enunciados, llega al campo de la vida práctica, mostrando gran preocupación por aquellas realidades que atentan a la vida de los hombres que niegan su dignidad como hijos de Dios y ciudadanos del mundo. (63)

El documento conciliar señala que las desigualdades sociales tienden a endurecerse y producen un retroceso en las condiciones de vida económica, que no siempre se ordena de forma racional y humana. Mientras muchedumbres inmensas están privadas de lo estrictamente necesario, algunas, aun en los países menos desarrollados, viven en la opulencia. Un reducido número de personas disponen de altísimo poder de decisión, otros están privados de toda iniciativa y responsabilidad en condiciones de vida indignos de la persona humana. Los hombres de nuestro tiempo son cada vez más sensibles a estas desigualdades, por eso exigen profundas reformas en la vida económica y social y un cambio de mentalidad y de hábitos.

(64) El desarrollo económico debe quedar bajo el control del hombre y no al solo arbitrio de unos pocos hombres o grupos dotados de excesivo poder económico, no se ha de dejar en manos de la sola comunidad política, ni de algunas grandes potencias. No se puede dejar el desarrollo ni al juego casi mecánico de las fuerzas económicas ni a la sola decisión de la autoridad pública. El poder civil debe reconocer el derecho y deber de los ciudadanos a contribuir al auténtico progreso de la vida de la comunidad.

En el ( $\left.\mathrm{N}^{\circ} 73\right)$ el Concilio proclama la dignidad de las personas ante la crisis del orden jurídico y político y la responsabilidad de todos en la realización del bien común. Establece la naturaleza de la comunidad política, el fin que persigue y el modo de ejercer el poder público en orden a 
conseguir el bien de todos, junto al progreso económico, cultural y social está el deseo de participar decididamente en el ordenamiento de la comunidad política, se reprueba las formas políticas que coartan la libertad civil o religiosa, multiplican los crímenes políticos y desvían del bien común, el ejercicio de la autoridad para hacerle servir al provecho de ciertos sectores o de los mismos gobernantes.

En el numeral 74 la Constitución Gandium et Spes habla de la naturaleza y fin de la comunidad política, esta nace, dice, de la búsqueda del bien común; en él se encuentra su sentido y plena justificación y de la que saca su exclusiva legitimidad. El bien común abarca todas las condiciones de la vida social que permiten a los hombres, a las familias y a las asociaciones conseguir plenamente su propia perfección. La comunidad política y la autoridad pública tienen su fundamento en la naturaleza humana y por eso pertenecen al orden previsto por Dios, aun cuando la determinación de los regímenes políticos y la designación de los gobernantes se dejan a la libre decisión de los ciudadanos. (75) Es conforme con la naturaleza humana que se encuentren estructuras jurídico-políticas que den a todos los ciudadanos, de modo cada vez mejor y sin discriminación el participar libre y activamente, tanto en la determinación de los fundamentos jurídicos de la comunidad política como en la gestión de los asuntos públicos, en la fijación de los campos de acción de los diferentes organismos del Estado, en la determinación de los fines y en la elección de los dirigentes.

Los cristianos deben tener conciencia del papel particular y propio que les toca en la comunidad política, en la que están llamados a dar ejemplo desarrollando en sí mismos el sentido de responsabilidad y de consagración al bien común, armonizando autoridad y libertad, iniciativa personal y solidaridad del cuerpo social, la unidad y la diversidad. En la administración de lo temporal sepan reconocer la existen- 
cia de opciones diversas y a veces contradictorias, pero legítimas. Al final del numeral 75 el documento conciliar recomienda la educación cívica y política, que en nuestros días es necesaria para el conjunto del pueblo, ante todo para los jóvenes, a fin de que todos los ciudadanos puedan desempeñar su papel en la vida de la comunidad política. Los que son o pueden llegar a ser, capaces de ejercer un arte tan difícil, pero a la vez tan noble, cual es la política, prepárense para ella y no rehúsen dedicarse a la misma, sin buscar el propio interés, ni ventajas materiales.

Luchen contra la injusticia y la opresión, contra la intolerancia y el absolutismo, sea de un hombre o de un partido, obren con integridad y prudencia y que se consagren al servicio de todos con sinceridad y rectitud; más aún: con amor y fortaleza política.

En el tema de la relación entre la Iglesia y la comunidad política (n. 76) establece claramente una distinción entre lo que obran los cristianos individual o asociadamente, como ciudadanos guiados por la conciencia cristiana y lo que se hace a nombre de la Iglesia con sus pastores. La Iglesia en su misión no se confunde con la sociedad civil, ni está ligada a ningún sistema político. La comunidad política y la Iglesia son autónomas e independientes en el propio campo de cada una. Ambas por razones diversas, están al servicio personal y social de la misma comunidad humana por eso se debe procurar una sana colaboración, Gandium et Spes, constituye una auténtica novedad en la historia de los concilios, es la primera vez que un concilio habla de problemas económicos, sociales, políticos, provocando ciertas desconfianzas.

Antoncich señala, que "estos temas entraron en el Concilio gracias a un concepto clave, que permite comprender los problemas de la sociedad, de la historia humana, como interpelaciones a la misión de la Iglesia. Este concepto clave es el de "signos de los tiempos". Gracias a este 
concepto, originariamente bíblico (cf.Mt. 16:1-4) entran en el Concilio preocupaciones temporales del mundo". Esta expresión pone a la historia humana, bajo la mirada de la fe y de la reflexión teológica, permitiendo conocer mejor la voluntad y el designio de Dios sobre la historia ${ }^{10} .-10$

\section{Medellín-Puebla-Santo Domingo}

El Concilio Vaticano II y particularmente "Gandium et Spes" y el concepto signos de los tiempos van a ser retomados con fuerza en la Iglesia de América Latina efectivamente, las conferencias de Medellín y Puebla hacen de la lectura de los signos de los tiempos una tarea profética, una apertura a la llamada de Dios. Medellín clama desde la situación concreta del hombre y la mujer latinoamericanos sumidos en una situación de injusticia y opresión.

Retomemos algunas afirmaciones de Medellín, de Puebla, de Santo Domingo que se hacen eco de Vaticano II que toman los acontecimientos históricos como acción del hombre y acción de Dios llamando a la conversión. Los obispos contrastan la evangelización con la realidad social, no señalan solamente el escándalo de la brecha entre ricos y pobres y la necesidad de cambios económicos y políticos sino también dicen que se debe a estructuras sociales de pecado, al quebramiento de la moral social y personal, negación de la fe.

La Iglesia en Medellín dice que "El ejemplo y la enseñanza de Jesús, la situación angustiosa de millones de pobres en América Latina, las apremiantes exhortaciones de Papa y del Concilio, ponen a la Iglesia latinoamericana ante un desafío y una misión que no puede soslayar y al que debe responder con diligencia y audacia adecuadas a la urgencia de los tiempos" (M. 14-7). "Nadie puede negar la concentración de la propiedad empresarial, rural y urbana en pocas manos,

${ }^{10}$ ANTONICH, Ricardo: Los cristianos ante la injusticia. Ediciones Grupo Social. Bogotá. 1980. Pág. 91.

274 
haciéndose imperioso el reclamo de verdaderas reformas agrarias y urbanas así como la concentración del poder por las tecnocracias civiles y militares que frustran los reclamos de participación y de garantías de un estado democrático (P. 1263).

La Iglesia respeta la legítima autonomía del orden temporal y no tiene un modelo específico de régimen político. La Iglesia aprecia el sistema de la democracia en la medida en que asegura la participación de los ciudadanos en las opciones políticas y garantiza a los gobernados la posibilidad de elegir y controlar a sus propios gobernantes, o bien la de sustituirlos oportunamente de manera pacífica. (CA. 46).

Durante los últimos años de este proceso, la Iglesia ha jugado en América Latina y el Caribe un papel protagónico. En muchos países su acción sentó las bases para una convivencia basada en el diálogo y el respeto a la persona humana. Apoyada en el magisterio de su doctrina social, la Iglesia ha venido acompañando al pueblo en sus luchas y anhelos de una mayor participación y el estado de derecho". (190).

"La libertad, inherente a la persona humana y puesta de relieve por la modernidad, viene siendo conquistada por el pueblo en nuestro continente y ha posibilitado la instauración de la democracia como el sistema de gobierno más aceptado, aunque su ejercicio sea todavía más formal que real". (191).

"La convivencia democrática, que se afianzó después de Puebla, en algunos países se ha venido deteriorando, entre otros factores, por los siguientes: corrupción administrativa, distanciamientos de los liderazgos partidistas con relación a los intereses de las bases y las reales necesidades de la comunidad; vacíos programáticos y desatención de lo social y ético-cultural de parte de las organizaciones partidistas; gobiernos elegidos por el pueblo, pero no orientados eficazmente al bien común; mucho clientelismo político y populismo, pero poca participación". (192). 
- "Proclamar insistentemente a la sociedad civil los valores de una genuina democracia pluralista, justa y participativa.

- lluminar y animar al pueblo hacia un real protagonismo.

- Crear las condiciones para que los laicos se formen según la Doctrina Social de la Iglesia, en orden a una actuación política dirigida al saneamiento, al perfeccionamiento de la democracia y al servicio efectivo de la comunidad.

- Orientar a la familia, a la escuela y a las diversas instancias eclesiales, para que eduquen en los valores que fundan una auténtica democracia: responsabilidad, corresponsabilidad, participación, respeto de la dignidad de las personas, diálogo, bien común". (193).

"Son derechos sociales: Derecho a la educación, a la asociación, al trabajo, a la vivienda, a la salud, a la recreación, al desarrollo, al buen gobierno, a la libertad y justicia social, a la participación en las decisiones que conciernen al pueblo y a las naciones". (P. 1272) ${ }^{11}$.

"Toda la población, muy especialmente las clases populares, han de tener, a través de estructuras territoriales y funciones una participación receptiva y activa, creadora y decisiva en la construcción de una sociedad. (M. 1,7 $)^{12}$

"La autoridad pública tiene la misión de propiciar y fortalecer la creación de mecanismos de participación y de legitima representación de la población o si fuera necesario, la creación de nuevas formas" (M. 1,16).

"El creciente empobrecimiento en el que están sumidos millones de hermanos nuestros hasta llegar a intolerables extremos de miseria es el más devastador y humillante

\footnotetext{
${ }^{11}$ PUEBLA-CELAM: La evangelización en el presente y en el futuro de América Latina. 1979.

${ }^{12}$ MEDELLIN-CELAM: Iglesia y liberación humana. 1868. 
flagelo que vive América Latina y el Caribe. Así lo denunciamos tanto en Medellín como en Puebla y hoy volvemos a hacerlo con preocupación y angustia.

- La política de corte neoliberal que predomina hoy en América Latina y el Caribe profundiza aún más las consecuencias negativas de estos mecanismos. Al desregular indiscriminadamente el mercado, eliminarse partes importantes de la legislación laboral y despedirse trabajadores, al reducirse los gastos sociales que protegían a las familias de trabajadores, se han ahondado aún más las distancias en la sociedad.

- Tenemos que alargar la lista de rostros sufrientes que ya habíamos señalado en Puebla (cf. DP 31-39), todos ellos desfigurados por el hambre, aterrorizados por la violencia, envejecidos por infrahumanas condiciones de vida, angustiados por la supervivencia familiar. El Señor nos pide que sepamos descubrir su propio rostro en los rostros sufrientes de los hermanos". (179).

Estos textos nos muestran cómo la Iglesia de América Latina se apropia de los anhelos de justicia, de liberación de los más pobres. No se entiende a sí misma solo desde la visión del mundo moderno que le da Vaticano II, sino habla desde el grito de los oprimidos, desde su opción por los pobres, establece una nueva relación Iglesia - Sociedad. Pone como fundamento de la democracia a la persona humana en su dimensión y vocación social y comunitaria, porque el destino de la persona está ligado al de los demás, al bien común. La democracia es una opción ética: es el valor de la persona y su dignidad de sujeto y protagonista lo que demanda una sociedad organizada democráticamente, de modo que todos con libertad descubran su responsabilidad en el "bien común", participe en la toma de decisiones y en la construc- 
ción de un proyecto común de vida social, de vida para todos donde se realicen los proyectos personales.

Los documentos citados, piden participación activa, creativa, cristianos comprometidos en la construcción de un proyecto común, por eso también la democracia supone atención preferencial a los pobres, porque su pobreza y miseria es negación del proyecto común.

Vaticano II no hace referencia directa al tema de la democracia, los textos de la Iglesia de América Latina abundan en la descripción del contexto socio-económico, de los cambios culturales y políticos para ligar la democracia a los derechos humanos, los derechos de los pueblos, el ejercicio del poder, el bien común y la participación política.

La doctrina de la Iglesia nos ofrece una forma de entender la democracia, de practicar la política, de comprometerse con el bien común, frente a una concepción de la democracia fundamentada en la comprensión del ser humano como individuo productor y consumidor que se mueve fundamentalmente por sus intereses particulares, en competencia por el tener. La democracia se reduce al ejercicio del voto, de las libertades individuales, el ámbito privado de la vida frente al público. Lo público interesa si responde o no a los intereses particulares o corporativos como expresión de la suma de intereses particulares.

La democracia más que una situación dada es una realidad que se construye históricamente como expresión de lo que es y está llamada a ser la persona. Hay en este sentido algunos temas que debemos tocar, siguiendo la inspiración doctrinal de la Iglesia pero a la vez, retomando la práctica histórica.

\section{Opciones pastorales: líneas pastorales de la iglesia en el Ecuador}

La Iglesia ecuatoriana realizó un gran esfuerzo tanto en la aplicación de las directrices del Concilio Vaticano II, como 278 
en los aportes para las Asambleas de Medellín, Puebla, Santo Domingo; cada una de las Diócesis del país, luego de consultar en las Parroquias y Vicarías enviaron documentos a la Conferencia Episcopal para la elaboración del documento de aporte.

Posteriormente, a la publicación de los textos oficiales de las Conferencias Latinoamericanas, se realizó el mismo proceso para la aplicación en cada diócesis y la elaboración de los planes pastorales, estos procesos generaron una dinámica nueva, una nueva metodología, nuevos criterios, como lo indica opciones pastorales:

1. Partir del conocimiento de la realidad económica, social, cultural, política, religiosa en la que vivimos.

2. Iluminar la realidad desde la Palabra de Dios.

3. Opción preferencial por los pobres, los jóvenes, la familia.

4. Depositar nuestra confianza en el potencial evangelizador de los pobres.

5. Hacernos presentes en el seno de fuerzas y organizaciones populares.

6. Valorar los medios pobres.

7. Coherencia de fe y vida.

8. Aceptar ser signos de contradicción.

9. Buscar afanosamente la verdad y la justicia.

10. Dar importancia al nombre comunitario.

11. Impulsar la construcción de una Iglesia misionera. OP-(59). ${ }^{13}$

${ }^{13}$ OPCIONES PASTORALES. Conferencia Episcopal Ecuatoriana. N. 59. 1980. 
En el mismo sentido expuesto y constatando el deterioro económico, político que vive el país $(45,49-O P)$ considera que "el pueblo en su totalidad y particularmente a través de sus organizaciones propias, construye la nueva sociedad pluralista, los constructores de la nueva sociedad asumen su misión en espíritu de servicio al pueblo (P: 1249) al que deben estar vinculados, formar parte de él. La Iglesia dé su aporte específico a la construcción de esta nueva sociedad para el pueblo, con el pueblo (P: 1220) OP. 154.

Las líneas pastorales y el plan global de pastoral 2001-2010 toman con fuerza el tema de la democracia, la Iglesia se lamenta, de la creciente desilusión en el pueblo, por las rivalidades de los grupos de poder y los partidos, la pérdida de credibilidad, por la corrupción y el anteponer los intereses económicos de un pequeño grupo a los grandes intereses del conjunto de la sociedad. (LP: 324- 330). ${ }^{14}$

No debemos quedarnos solo en el conocimiento de la realidad sino buscar transformarla y para ello es necesario denunciar proféticamente las causas de la situación de miseria - denunciar los aspectos políticos de corte neoliberal, que profundiza cada vez más, la brecha entre ricos y pobres. Los países ricos no pueden eludir su responsabilidad. Es menester que se consoliden las organizaciones y movimientos populares, en defensa de los pobres buscando la unidad para la defensa de la vida. (LP: 375) "Vivimos un drama profundo, sumidos en la competencia injusta, la destrucción de los recursos naturales, el desempleo, la deuda externa, la discriminación y el deterioro de los servicios públicos y sobre todo la miseria y pobreza de las grandes mayorías, frente a la opulencia de los países industrializados" ( PG: 139). ${ }^{15}$

${ }^{14}$ LÍNEAS PASTORALES. Conferencia Episcopal Ecuatoriana. 1994.

${ }^{15}$ PLAN GLOBAL DE PASTORAL DE LA IGLESIA ECUATORIANA. 2001-2010. Conferencia Episcopal Ecuatoriana. 2001. 
"La democracia, con frecuencia, ha quedado reducida al acto del sufragio, por falta de formación política y por la demagogia de los partidos. La carencia de ideologías serias y políticas de Estado, la notoria corrupción presente en el campo político, los intereses económicos convertidos en criterio de la política, han dado lugar a una generalizada indiferencia y abstención. Los movimientos y organizaciones de la sociedad civil, se van convirtiendo en nuevos actores en el campo político, pero aún falta claridad en su misión y propuestas alternativas" (PG: 145-148).

La línea pastoral Nro. 22 del plan es sociedad civil y política y su objetivo recoge la temática anterior: "Fomentar la construcción de una sociedad democrática, solidaria, justa, pensante, honrada, abierta a la interculturalidad, que respete el bien común y apoye el principio de subsidiariedad para lograr el ideal de una sociedad con valores humanitarios y evangélicos" (PG: pág. 151).

\section{Política y compromiso evangélico}

La carta apostólica, al comienzo del nuevo milenio de Juan Pablo II (49) nos recuerda que "a partir de la comunión intereclesial, la caridad se abre por su naturaleza al servicio universal, proyectándonos hacia la práctica de un amor activo y concreto con cada ser humano. Este es un ámbito que caracteriza de manera decisiva la vida cristiana, el estilo eclesial y la programación pastoral. El siglo y el milenio que comienza tendrán que ver todavía y es de desear que lo vean de modo palpable, a qué grado de entrega, puede llegar la caridad hacia los más pobres". ¿Podemos quedar al margen ante las perspectivas de un desequilibrio ecológico que hace inhabitables y enemigas del hombre vastas áreas del planeta? ¿O ante los problemas de la paz, amenazada a menudo con la pesadilla de guerras catastróficas? ¿O frente al vilipendio de los derechos humanos fundamentales 
de tantas personas, especialmente de los niños? "Muchas son las urgencias ante las cuales el espíritu cristiano no puede permanecer insensible". ${ }^{16}$

"La Iglesia en América". Exhortación Apostólica de Juan Pablo II, insiste que "el magisterio social de la Iglesia, no se cansa de invitar a la comunidad cristiana a comprometerse en la superación de toda forma de explotación y opresión", interviniendo de tan forma "que den a las estructuras sociales, políticas y económicas una configuración más justa y solidaria" $(18)^{17}$

"América necesita laicos cristianos que puedan asumir responsabilidades directivas en la sociedad. Es urgente formar hombres y mujeres capaces de actuar, según su propia vocación, en la vida pública, orientándola al bien común, en el ejercicio de la política, vista en su sentido más noble y auténtico, como administración del bien común" (44). Especial atención pone, el Santo Padre a la vocación de la mujer, por su aporte específico, al progreso de la humanidad. "Sin esta aportación -dice- se perdería algunas riquezas que solo "el genio de la mujer" puede aportar a la vida de la Iglesia y de la sociedad misma" (45).

Cuando la Iglesia se preocupa así, de lo político está cumpliendo su misión religiosa, porque de su misión religiosa derivan funciones, luces y energías que sirven para establecer y consolidar la comunidad humana, según la ley Divina, sin atentar a la autonomía de lo temporal.

Cuando el Papa hace su llamado en "La Iglesia en América" "a enfrentar los pecados sociales que claman al cielo" (56); nos está hablando de una identidad teológico-política, de una clara relación fe y política, de actores y nuevos escenarios de la política que va describiendo: Derechos humanos (57), Pobres y marginados (58), Deuda Externa (59), Corrupción (60), Drogas (61), Carrera armamentista (62), Cultura de la

\footnotetext{
${ }^{16}$ JUAN PABLO II. Carta apostólica Novo Millenio Ineunte. Enero. 2001.

${ }^{17}$ JUAN PABLO II. Exhortación apostólica Ecclesia un América. Enero. 1999. 
muerte y sociedad dominada por los poderosos (63), discriminación de los pueblos indígenas y afroamericanos (64), Migraciones (65).

La santidad política, anunciada por algunos teólogos, exige hoy una espiritualidad de diaconía de servicio en el bien común, de llevar la buena nueva del Evangelio al mundo de la acción política, de la economía, de la cultura y que se fundamenta en el amor misericordioso de Dios por la humanidad, que siente en carne propia el dolor de su pueblo. A modo de Yahvé que conmovido "baja a salvar a su pueblo" (Ex, 3.8) que compasivo resuelve en amor las iras contra los opresores y no destruyéndolos (Os - 11, 8-9) que prefiere el camino de la encarnación de su Hijo al camino del exterminio de la humanidad.

Una espiritualidad que impulsa a transformar la sociedad, que postula un nuevo mundo, una sociedad con sabor a Reino de Dios. El rostro de nuestra América sufrida, que nos conmueve hasta las entrañas, que nos urge a una presencia política transformadora, liberadora, es el rostro impactante y misterioso del Señor, que nos llama, es el rostro sufrido del Siervo de Yahvé por estos "pecados sociales que claman al cielo".

Si queremos transformar nuestras sociedades, mejorar las condiciones humanas, en un mundo de exclusión de las grandes mayorías del banquete de la vida, es un imperativo ético, asumir nuestras obligaciones en la construcción de una nueva sociedad, hacerlo con solidaridad y responsabilidad para el logro del bien común global, para la redefinición de la democracia.

Este espíritu de servicio, de opción por la vida, por los pobres y excluidos es una dimensión de la Iglesia, que prolonga en la historia concreta de nuestra América Latina, la actitud de Jesús, que vino no a ser servido sino a servir y a dar su vida en rescate por muchos (Mc, 10, 46). El corazón de la santidad es el amor, que conduce incluso a dar la vida por los demás (Jn, $15,13)$. 
"La Iglesia de América Latina y el Caribe, dice el documento del CELAM: Tiene el gran reto de fortalecer su mística y su capacidad de servicio; y de abrir nuevos campos de participación en la construcción de una sociedad más justa y fraterna. En este esquema, continua el texto, los cristianos tenemos mucho que aportar y también la misma Iglesia, desde su propia institucionalidad. Por eso hay que despertar, alentar y subrayar la obligación de la participación de los laicos cristianos en el seno de la sociedad y, dicho de forma tajante, quien no se compromete en los cambios sociales, en las academias, gremios o sindicatos propios de su profesión o actividad, pierde derecho a la palabra. Somos sal de la tierra, luz del mundo y fermento en la masa, y pecamos gravemente cuando, por desidia, desinterés o simple comodidad, no asumimos la vocación a la cual Cristo nos Ilamó”. (365). ${ }^{18}$

\section{Iglesia: democracia y actores sociales}

La acción primordial de la Iglesia en el contexto actual es pues empeñarse en defender la vida, la inclusión digna de los excluidos, es decir, de las dos terceras partes de la humanidad huérfana del actual proceso de globalización. A través de la opción por los pobres, los cristianos hacemos presente al Reino de Dios, el cual se traduce en acciones políticas concretas, que promueven la justicia en la sociedad, la democracia social, económica, cultural, política.

Sin una pastoral social viva, creativa, articulada, esperanzada y esperanzadora, difícilmente la fe cristiana, tendrá un impacto sobre la realidad de injusticia, de violencia y corrupción presente con máscara de democracia la grave situación actual no ha logrado eliminar la capacidad

\footnotetext{
${ }^{18}$ CELAM. Los desafíos a la nueva evangelización. Bogotá. Julio 2002.
} 
de resistencia de nuestros pueblos, la presencia del Espíritu que desplega su fuerza y su sabiduría en la comunidad, que discierne y se compromete en iniciativas que asumen a la persona como el valor supremo de la Creación. La esperanza se resiste a morir en el corazón de los pobres y su esperanza se concreta en el rescate de valores sustanciales, en la dignificación de los excluidos, en la economía solidaria, en nuevas formas organizativas, en la participación que hace de cada creyente, un protagonista de la historia. La esperanza cristiana es una vocación a la responsabilidad histórica. (473).

Construir una nueva relación entre fe y política exige desprivatizar la fe, recuperar y afirmar su carácter público. El terreno de lo político es todo lo que está implicado en el término sociedad y no solamente la relación formal con el Estado. En la sociedad todo tiene una dimensión política. La recuperación del carácter público de la fe, no significa recolocar a la Iglesia en el ámbito estatal, desempeñando funciones legimitadoras. El carácter público-político de la fe se plantea, "desde la sociedad" y esto es lo que permite también una nueva relación de teología y política, de teología y cambios radicales en la sociedad, y más hoy con la carencia de ideologías serias y políticas de Estado, la notoria corrupción presente en el campo político, los intereses económicos convertidos en criterio de la política han dado lugar a una generalizada indiferencia y abstención de participar en la política. Vivimos en general en la Patria Grande una crisis de las instituciones políticas y una pérdida de credibilidad en ellas, toda esta realidad exige a nuestra Iglesia y en particular en nuestros países, a un paso necesario de la sociedad política a la sociedad civil.

La jerarquía en la Iglesia ya casi no tiene espacio para una presencia mediadora, de meros correctivos, tratando de evitar los abusos de los grupos de poder, en cada país, hoy es necesaria una actitud profética para cuestionar 
la lógica del sistema, los costos humanos, sociales, ecológicos de un proyecto de muerte y unirse decididamente a construir una nueva civilización, una nueva sociedad donde se respete la vida y no la presente idolatría que sacrifica vidas humanas en el altar del gran mercado, de la acumulación de riqueza y del consumo sin fin.

"El sistema llamado democrático, se parece cada vez más, a un gobierno de ricos y cada vez menos a un gobierno de pueblo. Imposible negar la evidencia: la masa de los pobres llamada a votar nunca es llamada a gobernar". "La pretendida democracia occidental ha entrado en una etapa de transformación retrógrada que no puede detener y cuyas consecuencias previsibles serán su propia negación. No hay necesidad alguna de que alguien tome la responsabilidad de liquidarla, ella misma se suicida todos los días". "Si no encontramos un modo de reinventarla, no perderemos solo la democracia, sino la esperanza de ver un día los derechos humanos respetados en este planeta. Sería entonces el fracaso más estruendoso de nuestro tiempo, la señal de una traición que marcaría la humanidad para siempre". (Saramago). ${ }^{19}$

Esta situación descrita, exige un lugar distinto a la presencia y visibilidad del cristianismo y de la Iglesia y nos lleva a enfrentar las dificultades que vienen del reduccionismo de la fe a la esfera de lo privado de forma que toda expresión pública de interés político que la fe pudiera alentar en el cristiano, es generalmente visto con sospecha. Nuestra Iglesia, no sin sacrificio y martirio, ha creado un espacio de encuentro fecundo entre la dimensión pública de la fe y la dimensión pública de lo político, nutriendo tanto lo político como lo religioso. La participación activa, la reflexión teológica, las celebraciones, las movilizaciones generalizadas en temas como: La deuda externa, el grito de los exclui-

${ }^{19}$ SARAMAGO, José: ¿Qué es la democracia? "Le Monde Diplomatique” 26. Agosto. 2004. 
dos, el ALCA, TLC, La Paz, la globalización de la esperanza, la ecología, el feminismo, los movimientos étnicos, culturales, etc., en los que se ha dado una activa presencia de grupos cristianos, nos demuestran, desde la práctica de los pobres, cómo la fe tiene una dimensión pública, histórica, cierta y efectiva y como desde lo religioso que genera opinión, se alimentan nuevas prácticas sociales, formas culturales, posiciones políticas.

"Es notorio que el cristianismo posconciliar y sobre todo de base popular latinoamericana ha asumido sin tapujos, criterios y posturas consideradas políticas, en la medida en que abordaban problemas y temas reservados anteriormente para los partidos políticos o los movimientos sociales: con esto quedaba roto el rigor "secular" de la praxis política, a la par que de las masas a un nuevo imaginario religioso y teológico, que terminó por resignificar muchas categorías y concepto políticos, así como el sentido de las movilizaciones sociales y el propio rol de la liturgia, la Biblia, los pastores y obispos y la misma Iglesia, realidad que no ha sido admitida del todo en la Iglesia Universal" "Como Iglesia no acabamos de comprender la importancia que tiene en nuestros países ese desplazamiento de los poderes políticos, desde las organizaciones y partidos nacidos con la Europa ilustrada, hacia las identidades sociales, que se agrupan en la sociedad civil y los movimientos surgidos con la exclusión neoliberal". (Allan Mendoza). ${ }^{20}$

La relación de fe y política, de Estado e Iglesia en nuestros países, tiene su propia historia, en las que se repiten los intentos de privatización o secularización de la fe, o la reducción de la articulación política de los cristianos, con su presencia anónima en los partidos políticos de explícita nomenclatura cristiana, católica.

${ }^{20}$ MENDOZA, Allan: “Cristianismo y política”. Nro. 4. Ecuador. 
Hoy se debe emprender como necesidad urgente, la refundación de la razón de ser de la política la democracia, esta tarea demanda una presencia fecundante y explícita del cristianismo y repensar las relaciones entre religión, secularización y política. Solo una presencia eclesial, humilde y dialogante en este campo podrá recuperar para la Iglesia, la dimensión de ser testigos creíbles del Evangelio y una voz de esperanza, de cara a la crisis de la política en general de negación de la democracia superando la actitudes de auto-marginación de los espacios políticos conflictivos, recluyéndose en el espacio incontaminado de la privatización de la fe, o proclamando las doctrinas ante una práctica impositiva y destructora de la vida de nuestros pueblos.

De este modo, nuestro compromiso eclesial, evangélico, está llamado a representar una cierta anticipación germinal de lo nuevo y una profunda afinidad entre el acontecer histórico del Reino y una nueva práctica política global que haga posible la vida en el planeta.

Solo es creíble una Iglesia configurada por el principio de la misericordia: que escucha los clamores del pueblo empobrecido, reacciona ante ellos y rehace la piedad de Dios, para con su pueblo. Su esperanza es la de los excluidos de la tierra, su práctica eclesial a favor de la vida, erradicando el sufrimiento injusto, la muerte de los inocentes, desviviéndose por ofrecer y transitar caminos eficaces de justicia. Solo esta Iglesia está llena del gozo del Señor Resucitado que ha encontrado hasta las entrañas heridas de nuestro mundo y aunque la oscuridad parece seguir tan densa, brilla la claridad de su presencia como el Cristo de ayer y hoy, camino de conversión, de comunión, solidaridad y evangelización de las culturas. 